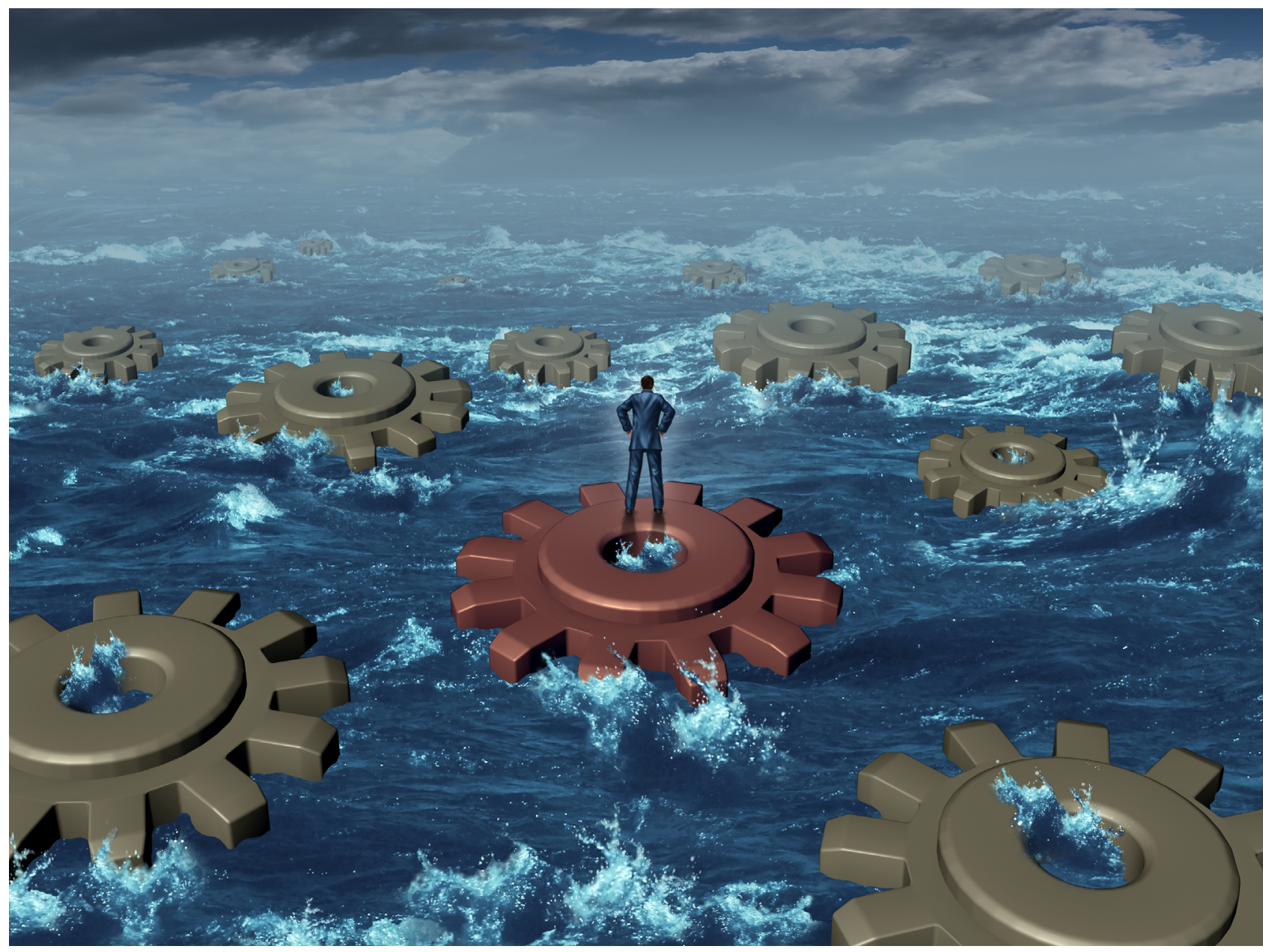

\title{
DESAFIOS DA ADMINISTRAÇÃO PÚBLICA BRASILEIRA
}

A CRISE DA COVID-19 EVIDENCIOU O PAPEL CENTRAL DA GESTÃO E BUROCRACIA PROFISSIONAL DO ESTADO, QUE PRECISA RESGATAR MECANISMOS DE AUTONOMIA DECISÓRIA, FORTALECER-

SE EM UM AMBIENTE DE COOPERAÇÃO E COORDENAÇÃO FEDERATIVA E PASSAR POR UMA REFORMA QUE ELIMINE DISTORÇÕES E FAVOREÇA SUA LEGITIMIDADE E PODER DE AÇÃO. 
A

pandemia exigiu uma miríade de respostas governamentais, demandando do Estado e, consequentemente, da administração pública, assumir o protagonismo no processo de gestão da crise. As políticas iniciais de distanciamento social foram acompanhadas por diversas outras intervenções, como o auxílio-emergencial para as populações vulneráveis, a ajuda financeira a setores econômicos e a mobilização de capacidades científico-tecnológicas para o desenvolvimento de vacinas e soluções terapêuticas. $\mathrm{O}$ conjunto dessas políticas foi responsável por expor a musculatura ou a fragilidade dos sistemas burocráticos em ação em cada contexto nacional e subnacional, em cada área de políticas públicas.

No Brasil, a crise vem servindo como teste de resiliência para a burocracia governamental, ao revelar as tensões com lideranças políticas; ao mostrar os obstáculos à adoção de políticas públicas baseadas em evidências diante de discursos negacionistas; ao explicitar as próprias desigualdades que ainda caracterizam a administração pública a partir de vários recortes - regionais, setoriais ou salariais -; ao levantar debates e discussões sobre a própria legitimidade da burocracia, materializados no novo processo de reforma administrativa; e, por fim, ao tensionar as relações entre os entes federativos.

\section{PANDEMIA E CONFLITOS FEDERATIVOS}

As relações entre os entes federativos foram conflitantes em toda a trajetória de enfrentamento à pandemia. Sem que houvesse uma política nacional pactuada com os estados, a União, por meio de conduta ditada pelo comportamento pessoal do presidente da república, sabotou as políticas de distanciamento social, já experimentadas em praticamente todo o mundo como as mais eficientes. As constantes trocas de chefia provocaram instabilidade na pasta central de combate à Covid-19, o Ministério da Saúde. Luiz Henrique Mandetta ficou no cargo por 470 dias, sendo demitido depois de ter sido exposto a um conjunto de constrangimentos públicos pelo chefe do Executivo. Nelson Teich permaneceu na função por apenas 29 dias, passando para a história como o ministro da Saúde mais breve a ocupar a pasta no período de redemocratização. Foi assim que o governo federal não assumiu o papel de coordenador de uma política nacional de combate à pandemia com os estados, como seria de se esperar em uma república federativa.

As tensões entre União e estados também acabaram repercutindo, em menor escala, em dificuldades nas relações entre governos estaduais e municípios. Ao desempenharem seus papéis de coordenadores das ações municipais, governos estaduais depararam com municípios sem estrutura e recursos prévios que dependiam da articulação entre estados e União para viabilizar alternativas à crise. $\mathrm{Na}$ falta de uma ação cooperada no enfrentamento da pandemia, escancararam-se as desigualdades entre os estados na luta contra a Covid-19, na medida em que estes passaram a depender inicialmente da mobilização dos seus próprios recursos. Revelou-se a precariedade do planejamento intergovernamental e, como consequência, explicitou-se a fragilidade do sistema federativo.

O dissenso em torno de como enfrentar a pandemia também se apresentou nas relações entre governos subnacionais. Prefeitos entraram em conflito com governadores ao decretar lockdowns quando esta não era a posição defendida pelo governo estadual. No sentido contrário, prefeitos não seguiram a orientação de governos estaduais de isolamento social quando as medidas causariam impacto econômico significativo às suas cidades. Por exemplo, municípios da Baixada Santista, em São Paulo, inclusive alguns governados por prefeitos filiados ao Partido da Social Democracia Brasileira (PSDB), mesmo partido do governador, recusaram-se a cumprir o decreto estadual que estabelecia o fechamento de atividades econômicas não essenciais no período de festas de fim do ano. A politização, decorrente sobretudo da priorização, por parte de alguns governantes, de manter a economia em pleno funcionamento em detrimento do distanciamento social, e do negacionismo em relação à letalidade da Covid-19 e até acerca da real existência do coronavírus, acabou sabotando o combate à pandemia.

\section{POLITIZAÇÃO, IDEOLOGIZAÇÃO E INAÇÃO}

A politização da burocracia pública manifestou-se de diversas formas, contaminando capacidades instaladas em diversos setores e encontrando seu ápice na gradual substituição da expertise técnica, historicamente dominante, pela expertise militar. O Sistema Único de Saúde (SUS), reconhecido internacionalmente não apenas pelo seu tamanho, como também pela sua capacidade testada no enfrentamento de outras emergências de saúde e pelo êxito de campanhas vitoriosas de vacinação (a exemplo da H1N1), foi gradualmente minado via crescente militarização dos mais altos cargos de gestão. A substituição da burocracia profissional do Ministério da Saúde, historicamente encarregado do papel de coordenação das políticas de saúde com estados e municípios, fragilizou tanto as políticas sanitárias baseadas em evidências necessárias para o enfrentamento da pandemia 
quanto os próprios princípios e procedimentos que caracterizam a administração pública no contexto democrático, a começar pelo da transparência.

A ideologização da administração pública afetou outros segmentos da burocracia, tradicionalmente profissionais, como os da diplomacia e da educação. As consequências despontam, com a perda dos canais diplomáticos necessários para negociar matéria-prima para a produção nacional de vacinas, além de danos ainda não mensuráveis em acordos comerciais com países como China, Índia e mesmo Estados Unidos. A pauta do Ministério de Educação foi por um bom tempo marcada pelas declarações de um dos ministros mais ideologizados do governo. Enquanto isso, o Brasil nunca discutiu um plano de educação adequado à pandemia, aprofundando o gap educacional.

A inação do governo federal em áreas como saúde e educação repercutiu na ponta de implementação de políticas públicas, afetando milhões de trabalhadores da linha de frente e comprometendo a qualidade de políticas públicas centrais para o bem-estar da população.

Por outro lado, a politização, a ideologização e a inação do centro do governo federal não imobilizaram totalmente as capacidades burocráticas do Estado brasileiro, como ilustrado pela resiliência de instituições públicas como Fundação Oswaldo Cruz (Fiocruz), Instituto Butantan, Agência Nacional de Vigilância Sanitária (Anvisa) e as iniciativas de inúmeras universidades públicas do país, mas impediram que essas capacidades instaladas fossem impulsionadas adequadamente para a gestão da crise.

\section{LEGITIMIDADE DA BUROCRACIA PÚBLICA}

Enquanto a crise evidenciou o papel central da administração pública e das instituições burocráticas, o contexto de recursos públicos cada vez mais escassos marcou a reabertura da discussão de um processo de reforma administrativa, materializado na Proposta de Emenda à Constituição (PEC) 32/2021, e, o mais importante, colocou na agenda política o debate acerca da própria legitimidade da burocracia pública.

Uma dupla motivação estrutura a proposta da PEC 32/2021: a tentativa de redução de gastos com o funcionalismo se alinha com a necessidade de construir as bases de uma burocracia mais justa, superando documentadas desigualdades no serviço público. Entretanto, focando quase exclusivamente em vínculos jurídicos individuais, a proposta é ambígua no que diz respeito à estabilidade e à profissionalização dos servidores públicos, trazendo mais desafios à consolidação de uma burocracia pública profissional no país.

Por outro lado, o Congresso está assumindo um protagonismo crescente na elaboração de uma proposta legislativa mais completa, que busque não apenas o resgate da legitimidade da burocracia profissional, eliminando as distorções e a desigualdade presente, mas também a capacidade de ação pública, imobilizada tanto pelas ingerências políticas como pelas várias formas de controle que paralisam a ação do gestor.

\section{DESAFIOS PÓS-PANDEMIA}

Essa breve análise da administração pública no combate à pandemia guia os desafios a serem enfrentados no pós-pandemia, alguns dos quais listamos no fim dessa resumida reflexão:

- Resgate de mecanismos institucionais que fortalecem a burocracia profissional: a pandemia revelou que politização, ideologização e populismo são ameaças sérias à burocracia profissional, cuja fragilidade, por sua vez, se traduz em perdas concretas em termos de políticas públicas. A resiliência de instituições vem de mecanismos institucionais que garantem sua autonomia decisória, como se pode verificar no caso da Anvisa ao aprovar o uso de vacinas no país;

- Fortalecimento de cooperação e coordenação federativas: é fundamental a compreensão da política como espaço de negociação e de construção de acordos, e não de conflitos que colocam em risco não apenas as relações intergovernamentais e entre os poderes, mas sobretudo a vida das pessoas; - Aperfeiçoamento da proposta da reforma administrativa: o avanço de uma reforma que tenha uma visão do setor público como um todo ainda é um imperativo para o pós-pandemia. $\mathrm{O}$ caminho passa por eliminar distorções, fortalecer a legitimidade da burocracia e criar condições favoráveis para a tomada de decisão proativa no setor público brasileiro.

\footnotetext{
PARA SABER MAIS:

- Fernando Luiz Abrucio, Eduardo José Grin, Cibele Franzese, Catarina lanni Segatto e Cláudio Gonçalves Couto. Combating Covid-19 under Bolsonaro's federalism: a case of intergovernmental incoordination. Revista de Administração Pública, v.54, n.4, 2020. Disponivel em: bit.ly/gvexecutivocombatingcovid

- Alketa Peci. 0 que esperar da nova proposta de reforma administrativa: uma análise da Proposta de Emenda à Constituição (PEC) 32/20. Revista de Administração Pública, v.54 n.6, 2020. Disponivel em: bit.ly/gvexecutivoreforma

Alketa Peci. A resposta da administração pública brasileira aos desafios da pandemia Revista de Administração Pública, v.54, n.4, 2020. Disponivel em: bit.ly/gvexecutivoadn

ALKETA PECI > Professora da FGV EBAPE > alketa.peci@fgv.br MARCO ANTONIO CARVALHO TEIXEIRA > Professor da FGV EAESP > marco.teixeira@fgv.br
} 